Article

\title{
Deposition of Titanium Dioxide Coating by the Cold-Spray Process on Annealed Stainless Steel Substrate
}

\author{
Noor irinah Omar ${ }^{1,2, *} \mathbb{0}$, Santirraprahkash Selvami ${ }^{1}$, Makoto Kaisho ${ }^{1}$, Motohiro Yamada ${ }^{1}$, \\ Toshiaki Yasui ${ }^{1}$ and Masahiro Fukumoto ${ }^{1}$ \\ 1 Department of Mechanical Engineering, Toyohashi University of Technology,1-1, Tempaku-Cho, Toyohashi, \\ Aichi 441-8580, Japan; santirraprahkash@gmail.com (S.S.); Kaisho.makoto.ik@tut.jp (M.K.); \\ yamada@me.tut.ac.jp (M.Y.); yasui@tut.jp (T.Y.); fukumoto@tut.jp (M.F.) \\ 2 Faculty of Mechanical Engineering and Manufacturing Technology, Technical University of Malacca, \\ Durian Tunggal, Melaka 76100, Malaysia \\ * Correspondence: noor.irinah.binti.omar.dj@tut.jp; Tel.: +81-080-9390-6329
}

Received: 18 September 2020; Accepted: 15 October 2020; Published: 17 October 2020

\begin{abstract}
The surface of most metals is covered with thin native oxide films. It has generally been believed that to achieve bonding, the oxide covering the surface of metallic particles or metal substrates must be broken and removed by adiabatic shear instability (ASI), whether induced at the particle-substrate interface or at the particle-particle interface. The aim of the present research is to investigate the correlation between the remaining oxide amorphous layer and substrate-deformation with the adhesion strength of cold-sprayed $\mathrm{TiO}_{2}$ coatings towards the bonding mechanism involved. Relevant experiments were executed using stainless steel (SUS 304), subjected to various annealing temperatures and cold-sprayed with $\mathrm{TiO}_{2}$ powder. The results indicate an increasing trend of coating adhesion strength with increasing annealed substrate temperature. The influence of substrate plastic deformation and atomic intermixing at the remaining amorphous oxide layer is discussed as the factors contributing to the increasing adhesion strength of cold-sprayed $\mathrm{TiO}_{2}$ coatings.
\end{abstract}

Keywords: adiabatic shear instability (ASI); cold spray; titanium dioxide; bonding mechanism; adhesion strength; substrate deformation; amorphous interface layer

\section{Introduction}

Cold spraying is a process in which the powder particles are used to form a coating by means of ballistic impingement upon a suitable substrate. Powders range in particle sizes from 5 to $100 \mu \mathrm{m}$ and are accelerated by injection into a high-velocity stream of gas. The particles are then accelerated by the main nozzle gas flow and impacted on the substrate. Upon impact, the solid particles deform and create a bond with the substrate [1]. When solid particles are sprayed toward a substrate, there are various phenomena that are generally observed on the substrate surface in relation to the process parameters such as substrate hardness, ductility, velocity size, incident angle, etc. However, if the velocity of particles is sufficiently fast, they can be embedded in the surface through a deposition process [2]. Therefore, substrate properties such as hardness, temperature, and degree of oxidation play a significant role in the bonding between particles and substrate [3].

It is well known that cold spraying of ceramic materials can be difficult because cold spraying requires plastic deformation of the feedstock particles for adhesion to the substrate. The challenge lies in the difficulty of plastically deforming hard and brittle ceramic materials, such as $\mathrm{TiO}_{2}$. Previous studies have reported the possibility of cold spraying thick pure $\mathrm{TiO}_{2}[4]$ but the bonding mechanism of cold sprayed $\mathrm{TiO}_{2}$ is not fully understood. 
Several experimental results have been published on the bonding mechanism of cold-spraying $\mathrm{Ti}$ or $\mathrm{TiO}_{2}$ particles onto metal and ceramic substrates. Winnicki et al. used a low-pressure cold-spray system for cold-sprayed amorphous, anatase, and rutile $\mathrm{TiO}_{2}$ powders with a particle size of $10-70 \mu \mathrm{m}$ and similar shape, which were prepared by the sol-gel process. The $100 \mu \mathrm{m} \mathrm{TiO}_{2}$ coatings were prepared on aluminum and the mechanism responsible for powder deposition was the mechanical interlocking of submicron powders with a local presence of agglomerates. They also indicate that the key parameter for the process seems to be the working gas temperature [5]. The same author also cold-sprayed amorphous and anatase $\mathrm{TiO}_{2}$ powder on the $\mathrm{ABS}$ substrate with varying gas temperatures of 200 and $300{ }^{\circ} \mathrm{C}$. The bond strength of the coating was tested using a tensile strength test machine and the highest value was $2 \mathrm{MPa}$ for $\mathrm{TiO}_{2}$ amorphous+anatase at 200 and $300{ }^{\circ} \mathrm{C}$ gas temperature [6]. Hajipour et al. cold sprayed two types of $\mathrm{TiO}_{2}$ powder; nanocrystal particles with a particle diameter of about $100 \pm 15.3 \mathrm{~nm}$ and agglomerating ultra-fine particle with a diameter of about $80 \pm 11 \mu \mathrm{m}$ on aluminum substrate. The thickness of the coating is about $490 \mathrm{~nm}$ for nanocrystal particles and 15-20 $\mu \mathrm{m}$ for the agglomerating ultra-fine particle. They indicated that for a brittle material such as $\mathrm{TiO}_{2}$, the first layer is achieved by plastic deformation of the ductile metallic substrate when the particles are embedded into the substrate without any additional binding agent or calcination procedure. The coating/substrate interface is relatively rough when the particle hits the substrate at a high speed. As a result, the titanium dioxide particles are embedded in the Al substrate. Roughness causes mechanical entanglement that might also play an important role in the buildup stage. They also conducted a coating bond strength testing by ultrasonic cleanout of $185 \mathrm{~W}$ for $1 \mathrm{~min}$. The adhesion was assessed according to the spalling state of the coating. They identified that there was no spalling of the coating after $1 \mathrm{~min}$ [7]. Schmidt et al. used 0.1-10 $\mu \mathrm{m}$ of $\mathrm{TiO}_{2}$ particles that were cold sprayed onto the flat polished surface of the titanium substrate. They identified that the plastic deformation of the substrate leads to a large continuous contact zone between the particles and the substrate and thus to durable bonding. They also tested the bond strength of the coating by ultrasonic cleaning with a maximum intensity of $40.8 \mathrm{~W} / \mathrm{cm}^{2}$. No local changes in the number, positions, and volumes of the particles could be observed after the cleaning cycle, indicating that the bonding of all the $\mathrm{TiO}_{2}$ particles to the substrate resists cleaning up to a maximum intensity of $40.8 \mathrm{~W} / \mathrm{cm}^{2}$ in the ultrasonic bath [8]. Kliemann et al. used 3-50 $\mu \mathrm{m} \mathrm{TiO}_{2}$ agglomerates formed from 5 to $15 \mathrm{~nm}$ of primary particles for continuous coating of steel, $\mathrm{Cu}, \mathrm{Ti}$, and $\mathrm{AlMg}_{3}$ substrates. They identified ductile substrates that allow shear instabilities to happen as the primary bonding mechanism between the particles and the substrate [9]. Gutzmann et al. obtained the impact morphology of single $\mathrm{TiO}_{2}$ particles and studied the deposition of different particles on substrates with different temperatures. They showed that there were concentric rings on the impacted substrates such as the shear instability zone. The deposition of a single $\mathrm{TiO}_{2}$ particle could be achieved only when the substrate temperature was above a certain value. The softer the substrate, the higher the deposition efficiency. It has been proposed that the preheating of the substrates could make them soft and facilitate the substrate shear instability, thus helping the deposit of the coating [10]. Gardon et al. reported that the mechanism responsible for the deposition of $\mathrm{TiO}_{2}$ on the stainless steel substrate in the cold-spraying process is the chemical bonding between the particles and the substrate. They have shown that the previous layer of titanium sub-oxide prepares the substrate with the appropriate surface roughness needed for the deposition of the $\mathrm{TiO}_{2}$ particle. In addition, the composition of the substrate is also important for deposition as it can provide chemical affinities during the particle interaction after impact. Substrate hardness may also ease the interaction between the particles and the substrate [11]. Salim et al. prepared 400 and $150 \mu \mathrm{m}$ $\mathrm{TiO}_{2}$ coatings on metal and tiles, respectively. They reported that the adhesion strength changed little with the changing spraying parameters. It was discovered that the hardness and the oxidizability of the substrate affected the adhesion strength of the $\mathrm{TiO}_{2}$ coatings. The adhesion strength of the $\mathrm{TiO}_{2}$ coatings could be improved by altering the surface chemistry of the substrate. It was proposed that the chemical or physical bonding mechanism can the main bonding mechanism for ceramic coatings [12], and that preheating could increase the oxidizability of the substrate, thus deteriorating the adhesion 
strength of the coating. The result seems to contradict Gutzmann's experiment, which showed that the preheating of the substrate improved the deposition of the $\mathrm{TiO}_{2}$ particle.

Clearly, there is still considerable uncertainty concerning the preheating of the substrate and the influence of any remaining amorphous oxide layer present at the interface of particle/substrate in relation to the bonding mechanism of cold sprayed $\mathrm{TiO}_{2}$. Therefore, to further understand the bonding mechanism of cold-spraying $\mathrm{TiO}_{2}$ onto metal substrates, in this study, we investigated the correlation between the remaining oxide amorphous phases after cold spraying, and their impacts on the particle/substrate interface toward the adhesion strength of agglomerated nano- $\mathrm{TiO}_{2}$ coatings on annealed metal substrates. Stainless steel (SUS 304) was chosen as the substrates to investigate the bonding mechanism involved and subjected to heat treatment of annealing. An annealing is a heat treatment that changes the physical and chemical properties of a material in order to improve its ductility and reduce its hardness, making it more workable [13]. By increasing the ductility of stainless steel after annealing at higher temperature, we expect better bonding between the $\mathrm{TiO}_{2}$ coating and the SUS 304 annealed stainless steel.

\section{Materials and Methods}

\subsection{Process}

In all coating experiments, the cold-spraying equipment with a De-Laval 24TC nozzle (CGT KINETIKS 4000; Cold Gas Technology, Ampfing, Germany) was used. Nitrogen was used as the process gas with a $500{ }^{\circ} \mathrm{C}$ operating temperature, and a $3 \mathrm{MPa}$ pressure. The spray distance was $20 \mathrm{~mm}$ with a process traverse speed of $10 \mathrm{~mm} / \mathrm{s}$. The coatings were deposited on a grit-blasted annealed stainless steel (SUS 304). The substrates were annealed with an electric furnace to preheat the grit-blasted substrate to four different temperatures, respectively (i.e., 300, 500, 700, and $1000^{\circ} \mathrm{C}$ ) before spraying. In all cases, the temperature of the annealed substrate during spraying was at room temperature.

\subsection{Materials}

As a feedstock, we applied agglomerated $\mathrm{TiO}_{2}$ powder (TAYCA Corporation, WP0097, Osaka, Japan) containing a pure anatase crystalline structure with an average particle size of about $7.55 \mu \mathrm{m}$, as shown in Figure 1. The material chemical composition of substrates used is presented in Table 1.

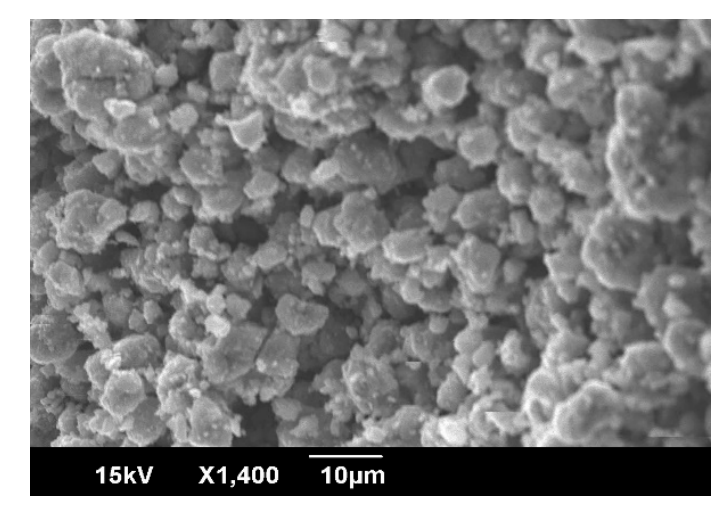

Figure 1. SEM morphology of $\mathrm{TiO}_{2}$ powder.

Table 1. Material chemical composition [wt $\%$ ].

\begin{tabular}{lllllclccc}
\hline Element & Fe & Cr & Ni & Mo & S & P & Mn & Si & C \\
\hline SUS 304 & Bal & 18 & 11 & - & 0.030 & 0.045 & 2.00 & 1.00 & 0.08 \\
\hline
\end{tabular}




\subsection{Characterization}

\subsubsection{Tensile-Strength Testing}

In accordance with JIS H 8402, specimens measuring $\varnothing 25 \times 10 \mathrm{~mm}$ were used to assess the coatings' adhesion strength, given as the fracture load value measured by a universal testing machine (Autograph AGS-J Series $10 \mathrm{kN}$, Shimadzu, Japan). We measured the adhesion strength over an average of five specimens for each of the spraying conditions.

\subsubsection{Coatings Evaluation}

A scanning electron microscope (SEM: JSM-6390, JEOL, Tokyo, Japan) was used to observe the $\mathrm{TiO}_{2}$ coating's cross-sectional microstructures on annealed substrates. The observation sample of the $\mathrm{TiO}_{2}$ coating was prepared by embedding a $25 \mathrm{~mm} \times 10 \mathrm{~mm}$ sample into a hardenable resin. The hardened sample embedded in the hardened resin was ground with silica papers to a \#3000 grit size and finally polished with 1 and $0.3 \mu \mathrm{m}$ alumina suspension.

\subsubsection{Micro-Vickers Hardness}

To investigate the relationship between the annealed substrate surface hardness and the adhesion strength of the $\mathrm{TiO}_{2}$ coating on the annealed substrate, the substrate hardness was measured using an HMV-G micro-Vickers hardness tester (Shimadzu, Japan). The measurement showed a hardness of HV 0.1 ; the test load on the cross section was $98.07 \mathrm{mN}$. The final micro-hardness value was the average of five tests taken at approximately the same points for each substrate.

\subsubsection{Substrate Oxide Evaluations}

X-ray photoelectron spectroscopy (XPS) is a versatile surface analysis technique used for compositional and chemical state analyses. In this study, XPS analysis (ULVAC-PHI, PHI Quantera SXM-CI, Kanagawa, Japan) using a monochromatic Al K $\alpha$ source $(15 \mathrm{~mA}, 10 \mathrm{kV})$ was performed. Wide $(0-1000 \mathrm{eV})$ and narrow scans of $\mathrm{Fe} 2 p, \mathrm{Cr} 2 p$, and $\mathrm{O} 1$ s for different annealed substrates were collected. The measured binding energies were then corrected with $\mathrm{C} 1 \mathrm{~s}$ at $285.0 \mathrm{eV}$. When pre-sputtering to clean the surface was performed, the sample surface was reduced and the measurements were affected, so XPS analysis was performed without pre-sputtering. Table 2 shows the XPS analysis conditions for substrates oxide analysis.

Table 2. XPS parameter for substrate oxide layer analysis.

\begin{tabular}{|c|c|}
\hline Measured Regions & Fe $2 p, \mathrm{O} 1 s, \mathrm{Cr} 2 p$ \\
\hline Measured X-Ray output [W] & 10 \\
\hline Probe diameter $[\mu \mathrm{m}]$ & 50 \\
\hline Time per step [ms] & 30 \\
\hline Pass energy & 140 \\
\hline Cycle & 30 \\
\hline
\end{tabular}

\subsubsection{Wipe Test}

A CGT Kinetiks 4000 cold-spray system (Cold Gas Technology, Ampfing, Germany) with a custom-made suction nozzle was used to perform the wipe test and coating using $\mathrm{TiO}_{2}$ powder onto the annealed $1000{ }^{\circ} \mathrm{C}$ stainless steel substrates. The wipe test was conducted to study the deformation behavior of a single particle on this substrate. Prior to deposition, the substrate was ground and polished until a mirror finish surface was obtained. The temperature of the process gas and the pressure used were $500{ }^{\circ} \mathrm{C}$ and $3 \mathrm{MPa}$, respectively. Nitrogen has been used as a process gas. The distance between the exit of the nozzle and the substrate was fixed at $20 \mathrm{~mm}$. The traverse speed of the process was $2000 \mathrm{~mm} / \mathrm{s}$. Prior to spraying, the substrates were rinsed with acetone. The FEI Helios Dual 
Beam 650 field emission SEM (FESEM, FEI, Oregon, USA) and focused ion beam (FIB, FEI, Oregon, USA) microscope was used to investigate the single particle $\mathrm{TiO}_{2}$ deposition on mirror polished annealed substrate.

\subsubsection{TEM Testing}

Single titanium dioxide particles were deposited on a $25 \mathrm{~mm} \times 25 \mathrm{~mm} 1000{ }^{\circ} \mathrm{C}$ annealed mirrored steel substrate (SUS 304). In this cold-spray process, nitrogen gas was used as the process gas. The distance between the exit of the nozzle and the substrate was fixed at $20 \mathrm{~mm}$. The process traverse speed was $2000 \mathrm{~mm} / \mathrm{s}$. Prior to spraying, the substrates were rinsed with acetone. Thin membranes for transmission electron microscopy (TEM, JEOL, Tokyo, Japan) observation were carefully made from deposited $\mathrm{TiO}_{2}$ particles onto annealed $1000{ }^{\circ} \mathrm{C}$ mirrored steel substrate by the focused ion beam (FIB) milling equipment (FEI Helios Dual Beam 650, FEI, Oregon, USA). Without further sample preparation, electron-transparent membranes were made and investigated by field emission gun (FEG) electron microscopy using a JEOL JEM-2100F FE-TEM with a scanning mode at an applied voltage of $200 \mathrm{kV}$. The elemental distribution of the membranes was acquired by means of STEM energy-dispersive X-ray spectroscopy (EDX).

\section{Results}

\subsection{Strength of Adhesion}

The adhesion strength of the cold-sprayed $\mathrm{TiO}_{2}$ coating on annealed SUS 304 stainless steel are shown in Figure 2. The $\mathrm{TiO}_{2}$ coating on the annealed hard substrates showed an increased trend of adhesion strength from room temperature to $1000^{\circ} \mathrm{C}$, with values from 0.51 to $2.55 \mathrm{MPa}$.

Figure 3 shows the fracture coating of $\mathrm{TiO}_{2}$ on annealed SUS 304 from room temperature to $1000^{\circ} \mathrm{C}$ after adhesion-strength testing. The interface fracture occurred between the coating and substrate for annealed SUS 304 substrates in all conditions, as shown in Figure 3a-e.

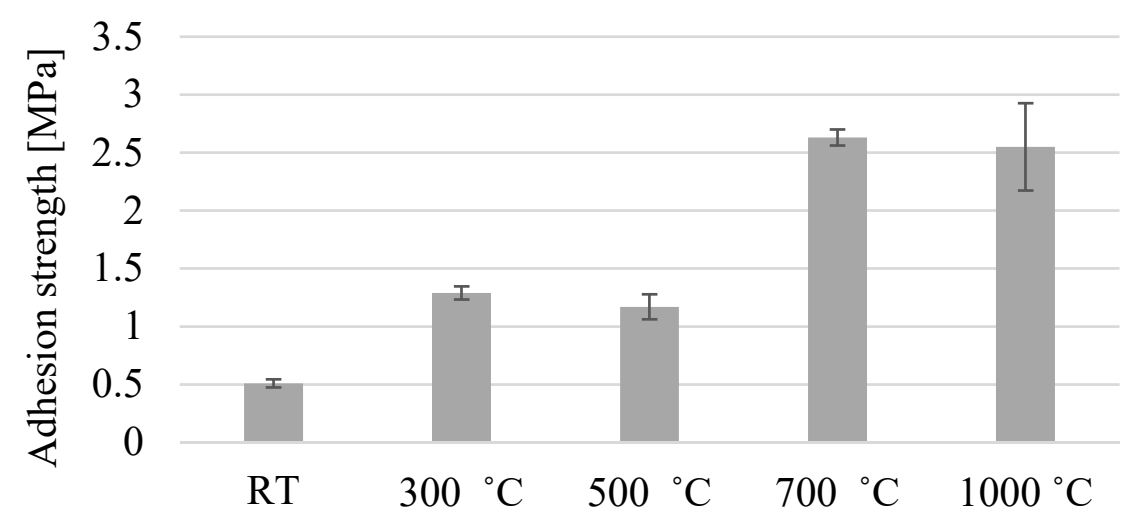

Annealed substrate temperature

Figure 2. Adhesion strength of the $\mathrm{TiO}_{2}$ coating on annealed SUS 304 . 


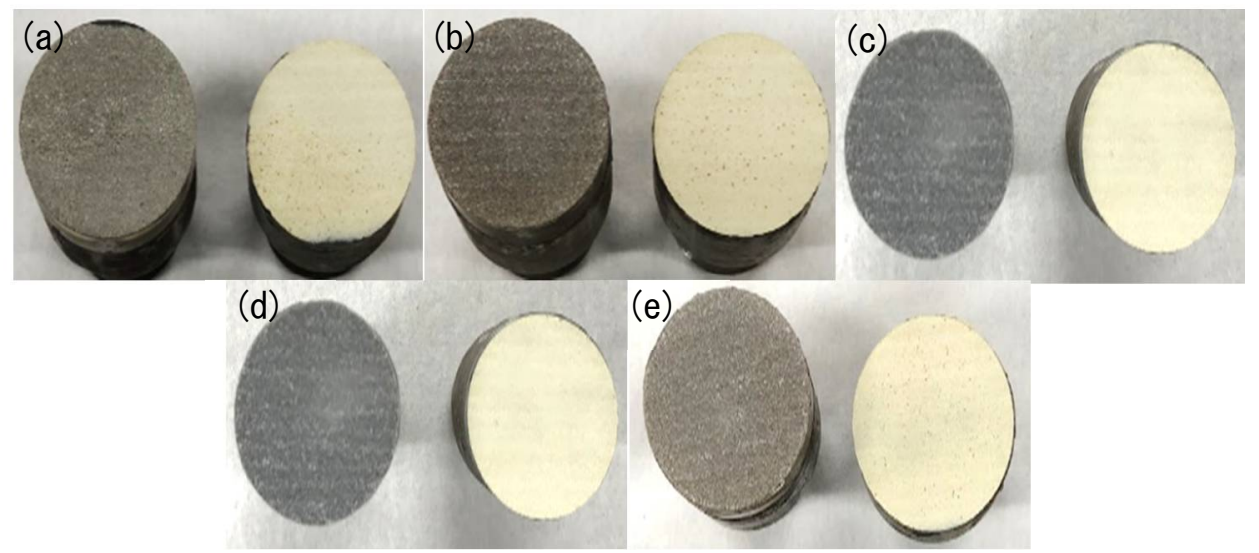

Figure 3. Fracture surface substrate and $\mathrm{TiO}_{2}$ coating after tensile strength testing on SUS 304. (a) Room temperature; (b) annealed at $300{ }^{\circ} \mathrm{C}$; (c) annealed at $500{ }^{\circ} \mathrm{C}$; (d) annealed at $700{ }^{\circ} \mathrm{C}$; and (e) annealed at $1000{ }^{\circ} \mathrm{C}$.

\subsection{SEM Cross-Section Microstructure of $\mathrm{TiO}_{2}$ Coatings on Annealed SUS 304 Substrates}

Figure 4a-e shows the $\mathrm{TiO}_{2}$ coating cross-sectional area on SUS 304 for various substrate annealing temperatures. The figures show, in all conditions, a dense coating with a thickness of $300 \mu \mathrm{m}$, indicating that a critical velocity was reached for this hard material. This suggests that the $\mathrm{TiO}_{2}$ coating adhered well to the annealed SUS 304 substrate from room temperature to $1000^{\circ} \mathrm{C}$ annealing.

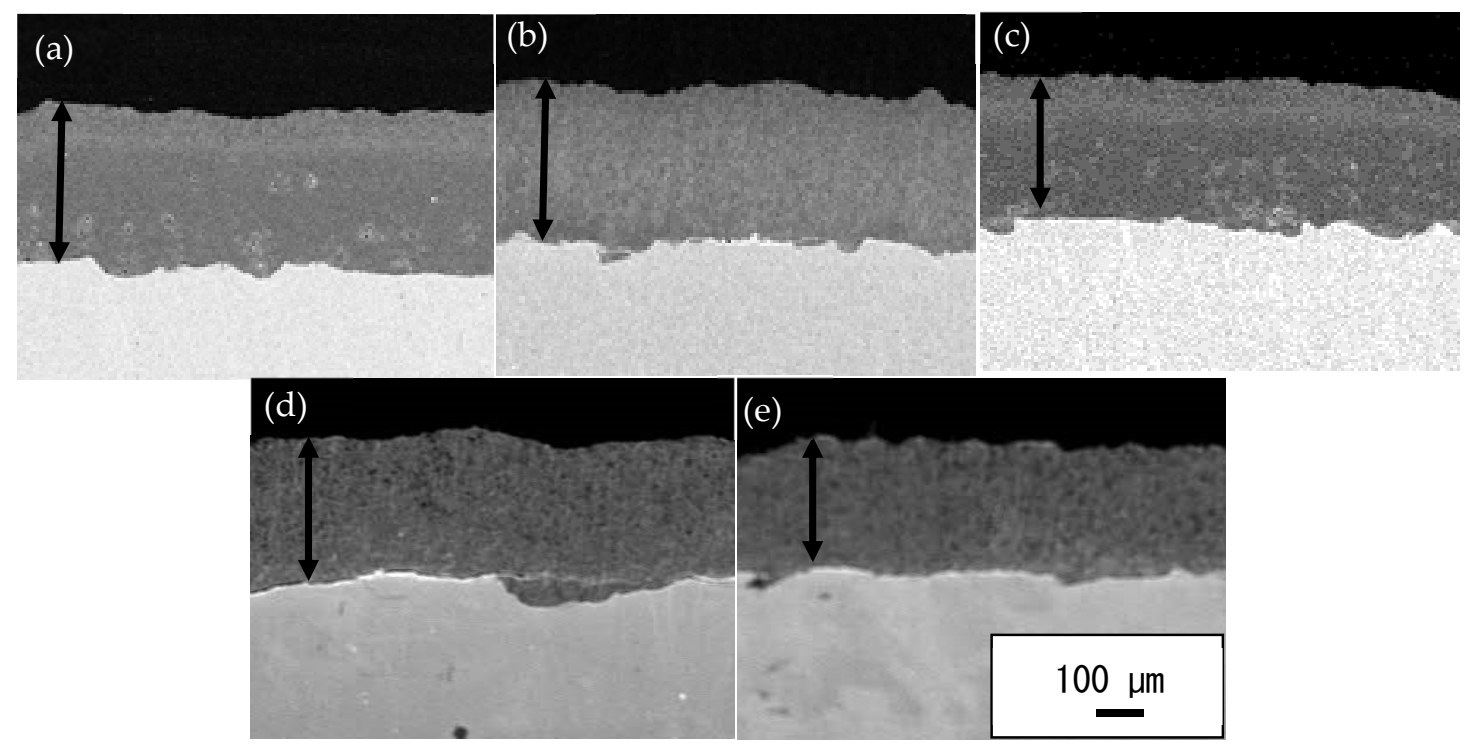

Figure 4. Cross-section microstructure of $\mathrm{TiO}_{2}$ coatings on SUS 304. (a) Room temperature; (b) annealed at $300{ }^{\circ} \mathrm{C}$; (c) annealed at $500{ }^{\circ} \mathrm{C}$; (d) annealed at $700{ }^{\circ} \mathrm{C}$; and (e) annealed at $1000{ }^{\circ} \mathrm{C}$.

We can categorize the cold-spraying procedure into two stages: (1) Adhesion and (2) cohesion bonding. Adhesion or the formation of the interface between the substrate and particle is the first stage. The annealed substrates can clearly implement this stage, which forms the first coating layer, particularly for the hard material, SUS 304.

\subsection{Substrate Vickers Microhardness}

Figure 5 shows the annealing substrate hardness of SUS 304 from room temperature to $1000{ }^{\circ} \mathrm{C}$. The stainless steel, SUS 304 showed a decreasing trend from $345.90 \mathrm{Hv}$ for room temperature to $173.00 \mathrm{Hv}$ for $1000{ }^{\circ} \mathrm{C}$ annealing. 
Based on the iron-carbon phase diagram, when the austenite stainless steel, SUS 304 is annealed at $1000{ }^{\circ} \mathrm{C}$, which is above the eutectoid temperature of $727^{\circ} \mathrm{C}$ and slow cooled in the furnace using air medium, the phase transformation involved is austenite to pearlite (ferrite + cementite). This microstructure transformation is associated with a reduction of substrate hardness for $1000{ }^{\circ} \mathrm{C}$ annealed SUS 304 and it becomes softer [13].

The reduction of the hardness of SUS 304 may be one of the factors that contributed to the trend of the increase in the $\mathrm{TiO}_{2}$ coating adhesion strength with increasing SUS 304 substrate annealing temperature. As the substrate becomes softer at higher annealed temperatures such as $1000{ }^{\circ} \mathrm{C}$ and when cold sprayed $\mathrm{TiO}_{2}$ impacts the substrate surface with a high impact velocity, it is associated with substrate deformation that may contribute to the bonding. The mechanical anchoring factor is discussed later in Sections 3.5 and 3.6.

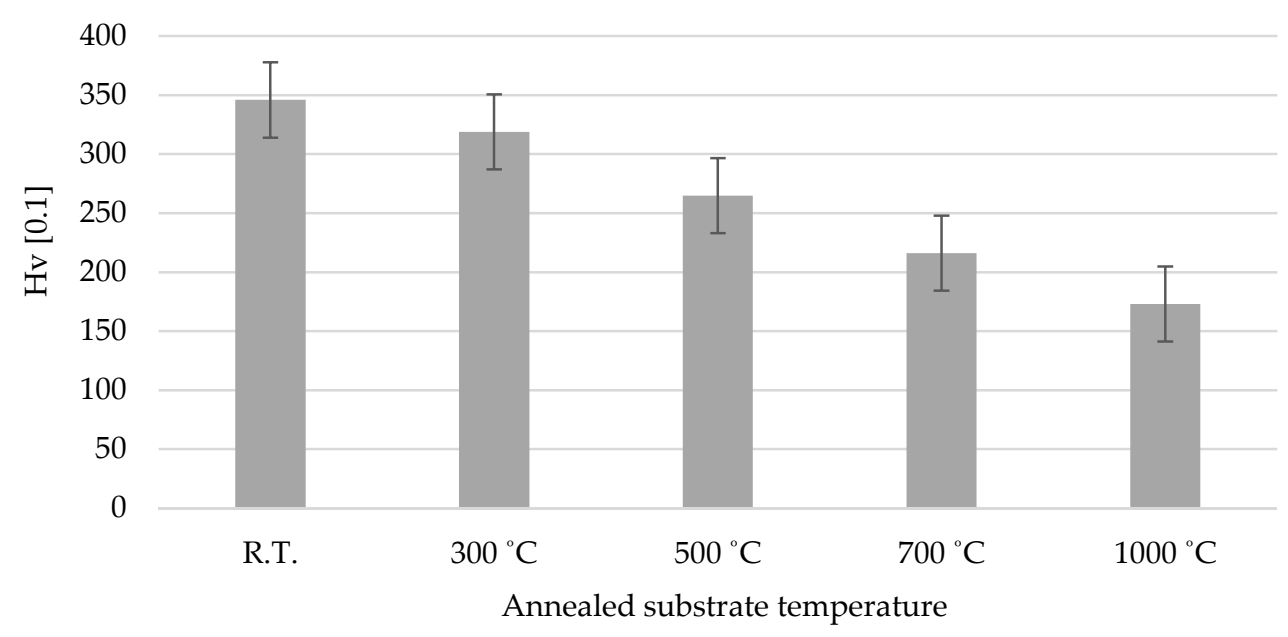

Figure 5. Annealed substrate microhardness of SUS 304 from room temperature to $1000{ }^{\circ} \mathrm{C}$ annealing.

\subsection{Depth Profile of the Oxide Layer}

The result of the depth analysis of room temperature substrate and annealed $700{ }^{\circ} \mathrm{C}$ by $\mathrm{X}$-ray photoelectron spectroscopy for the SUS 304 substrate is shown accordingly in Figure 6a,b. The atomic composition of oxygen in the deepest part of the oxide layer increases significantly as the annealing substrate temperature increases from RT to $700{ }^{\circ} \mathrm{C}$. This shows that the oxide layer of stainless steel grows thicker as the annealing temperature of the substrate increases. We also expect the oxide layer to be thicker on the annealed $1000^{\circ} \mathrm{C}$ SUS 304 substrate. 

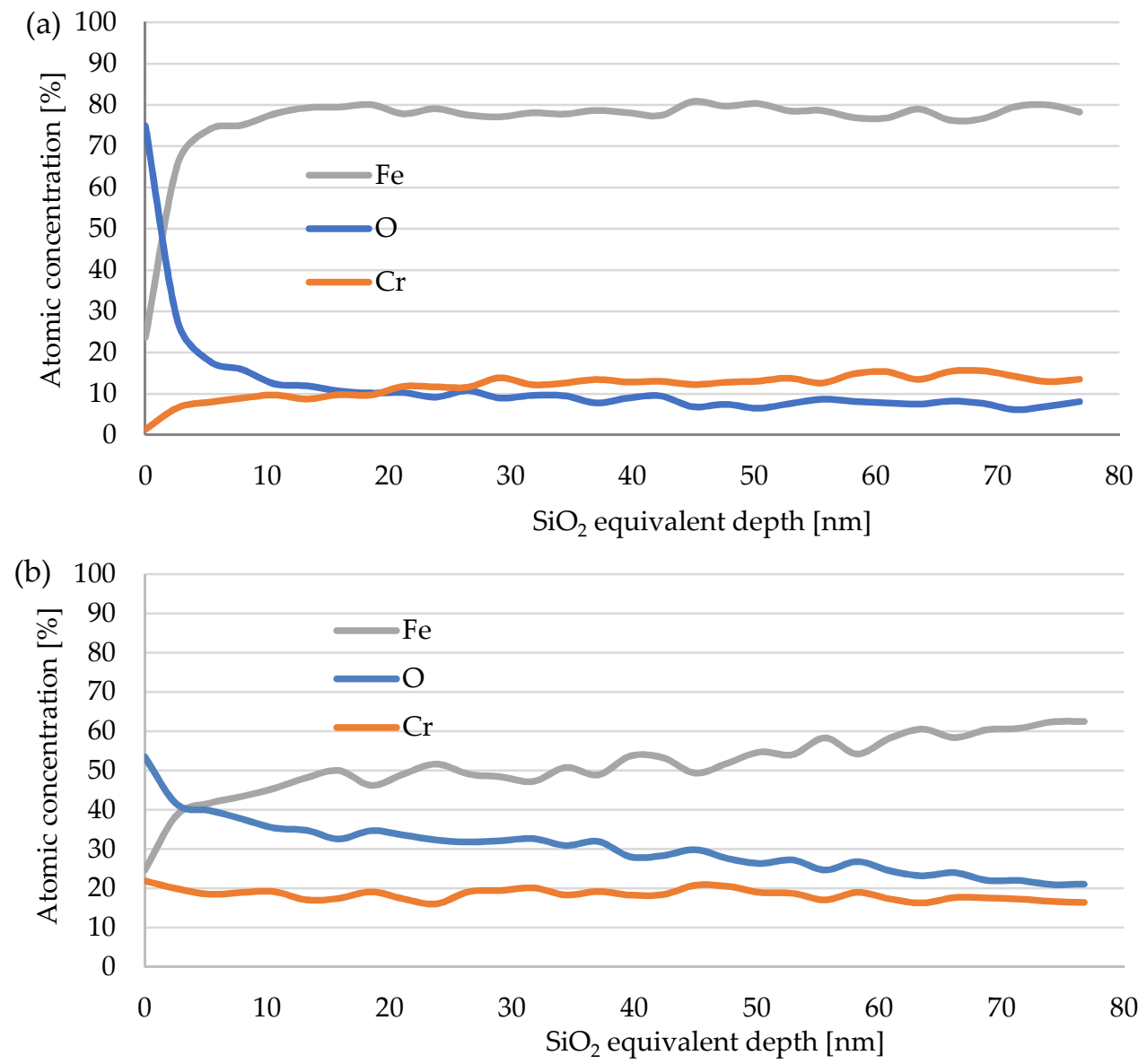

Figure 6. Depth profile analysis of SUS 304 stainless steel. (a) Room temperature, (b) annealed at $700{ }^{\circ} \mathrm{C}$.

\subsection{FIB Splat $\mathrm{TiO}_{2}$ Particle on $1000^{\circ} \mathrm{C}$ Annealed Substrates}

Figure 7 shows the FIB result of the $\mathrm{TiO}_{2}$ particles on the $1000{ }^{\circ} \mathrm{C}$ annealed SUS 304. This wipe test was conducted to further understand the bonding mechanism of the $\mathrm{TiO}_{2}$ particle on the annealed SUS 304 substrate. Only the $1000^{\circ} \mathrm{C}$ annealed SUS 304 was selected because it had a high adhesion strength. The results obtained revealed that the $\mathrm{TiO}_{2}$ particle was found unchanged after the collision and the substrate surface of the $1000{ }^{\circ} \mathrm{C}$ annealed SUS 304 experienced a deformation due to impacting during the cold-spraying process, as shown by Figure 7. A previous study undertaken by Trompetter et al. demonstrated that for a solid particle impacting on a substrate, the substrate hardness played a significant role in the as-produced solid particles [14]. This condition can be understood by the fact that SUS 304 experienced microstructure transformation during the annealing process at $1000^{\circ} \mathrm{C}$, therefore the substrates hardness was reduced and it became softer. 


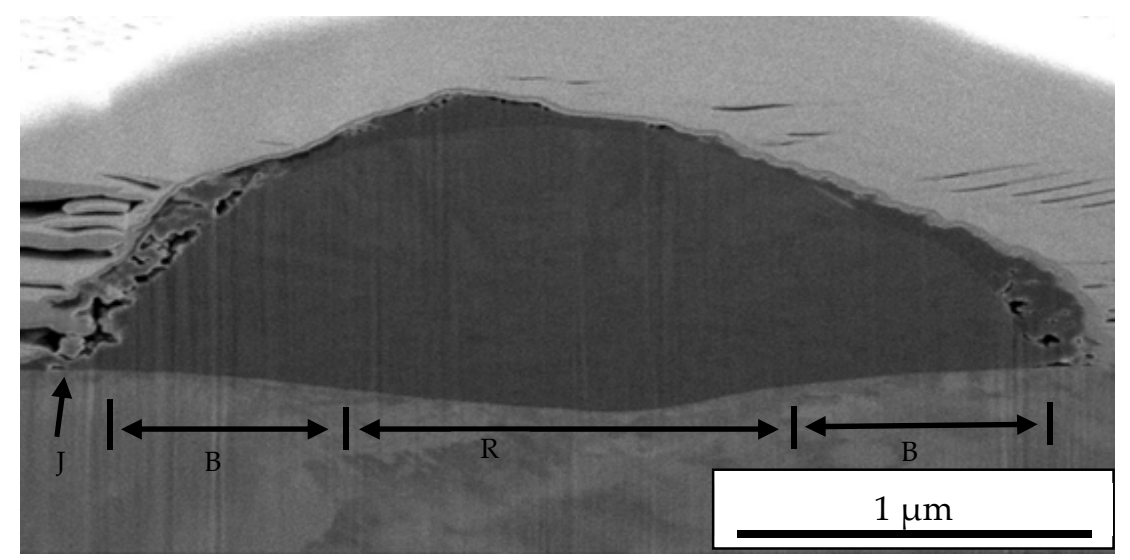

Figure 7. FIB cross-section of a single particle of $\mathrm{TiO}_{2}$ on $1000{ }^{\circ} \mathrm{C}$ annealed SUS 304. J indicates the jetted-out region; $\mathrm{B}$ is the bonded region; $\mathrm{R}$ is the rebound region.

Referring to Figure 7, since the shear instability starts at a position away from the bottom center of the $\mathrm{TiO}_{2}$ particle, the bottom region of the deposited particle can be divided into three regions along the particle-substrate boundary: (i) The particle jetted out region (J) generated by the severe shear plastic strain induced by adiabatic shear instability (ASI); (ii) the well-bonded region (B) where the particle and the substrate are intimately bonded; and (iii) the rebound region (R) where the shear instability did not occur and the accumulated elastic energy from the impact of a sprayed particle detached the particle from the substrate. At the boundary of B and R, ASI is accompanied by severe shear stress, and an abnormal increase in temperature can easily expel the particles, and consequently the oxide covering the surface of particle or substrate can be broken and removed [3,15-20].

The adhesion strength of the $\mathrm{TiO}_{2}$ coating on annealed SUS 304 showed an increased trend as the annealed substrate temperature is increased. This indicates that substrate deformation or mechanical anchoring is one of the factors that influence the adhesion bonding of the annealed SUS 304 with $\mathrm{TiO}_{2}$ at the annealing temperature of $1000{ }^{\circ} \mathrm{C}$. This result is supported by other reports of cold-sprayed $\mathrm{TiO}_{2}$ onto hard substrate such as titanium and stainless steel. Schmidt et al. used 0.1-10 $\mu \mathrm{m}$ of $\mathrm{TiO}_{2}$ particles that were cold sprayed onto the flat polished surface of a titanium substrate. They identified that the plastic deformation of the substrate leads to a large continuous contact zone between the particles and the substrate and thus to a durable bonding [8]. Kliemann et al. used 3-50 $\mu \mathrm{m} \mathrm{TiO}_{2}$ agglomerates formed from 5 to $15 \mathrm{~nm}$ of primary particles for the continuous coating of steel substrate. They identified ductile substrate that allows shear instability to happen as the primary bonding mechanism between the particles and the substrate [9].

\subsection{TEM Analysis on Interface Oxide Layer between $\mathrm{TiO}_{2}$ Particle on $1000{ }^{\circ} \mathrm{C}$ Annealed Substrates}

The TEM result is shown as the STEM image interface of the rebound region between single-particle $\mathrm{TiO}_{2}$ and $1000{ }^{\circ} \mathrm{C}$ annealed SUS 304, as shown by Figure 8. It confirms the existence of the remaining interface layer after the cold-sprayed $\mathrm{TiO}_{2}$ impacted, with a thickness of approximately $10 \mathrm{~nm}$ at the rebound region interface, $\mathrm{R}$ and $15 \mathrm{~nm}$ at the bonded region, $\mathrm{B}$ between single-particle $\mathrm{TiO}_{2}$, and $100{ }^{\circ} \mathrm{C}$ annealed SUS 304, as revealed in Figures 9 and 10. Kim et al. used kinetic spraying of single titanium particles on mirrored steel substrates. They showed that some portion of a thin amorphous oxide remained between the particle-substrate interface, and even a severe plastic deformation was associated with the impacts of the particles onto the substrate. The remaining oxide provided a bond between a particle or particle-substrate [21]. Our data also reported that the same, even interface thickness in the bonded region $B$ is thicker than in the rebound region, $R$. 


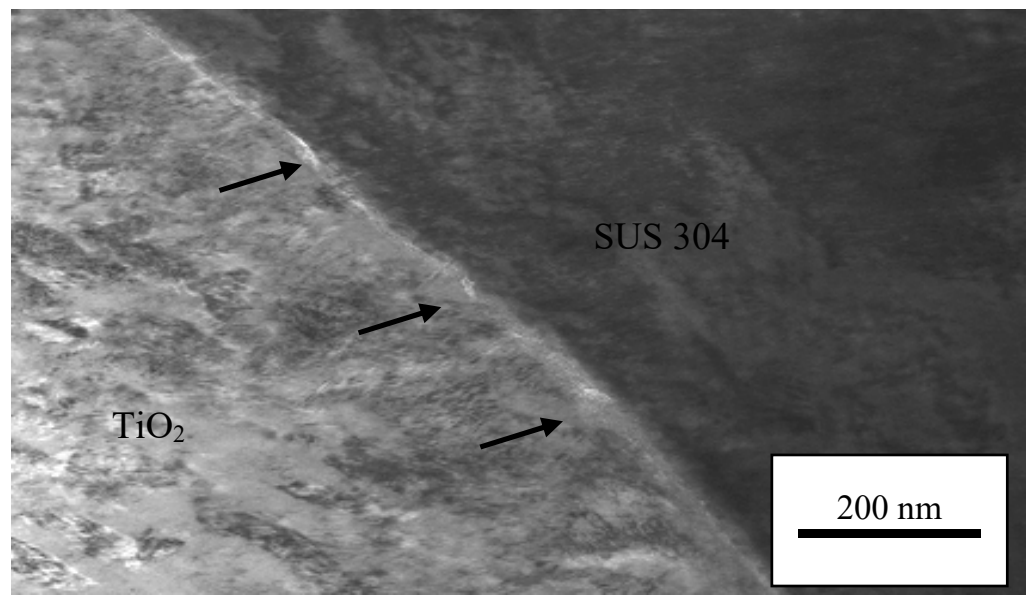

Figure 8. STEM of the $\mathrm{TiO}_{2} / 1000{ }^{\circ} \mathrm{C}$ annealed SUS 304 interface at the rebound region, $\mathrm{R}$.

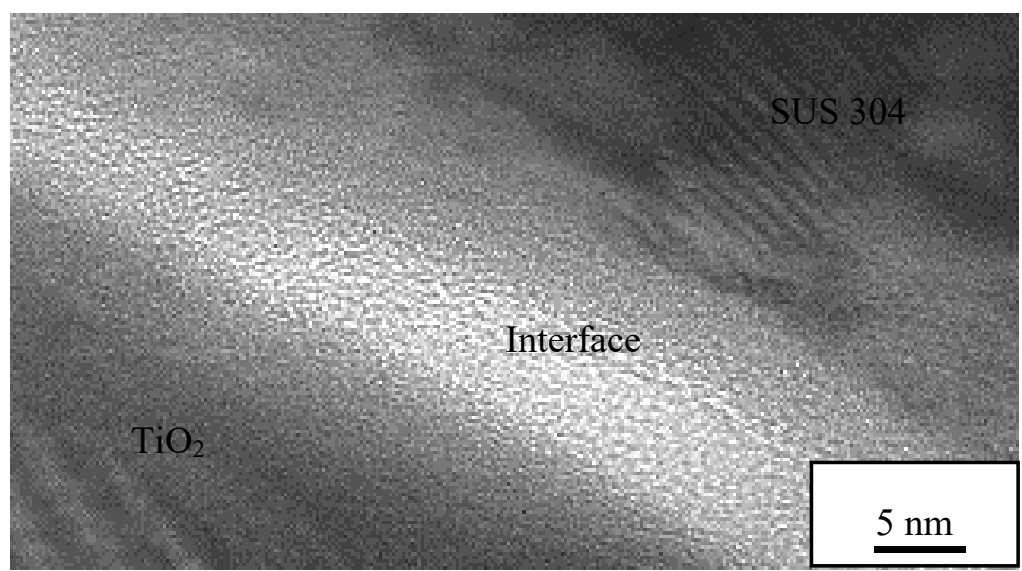

Figure 9. High-magnification images of the $\mathrm{TiO}_{2} / 1000{ }^{\circ} \mathrm{C}$ annealed SUS 304 interface at the rebound region, $R$.

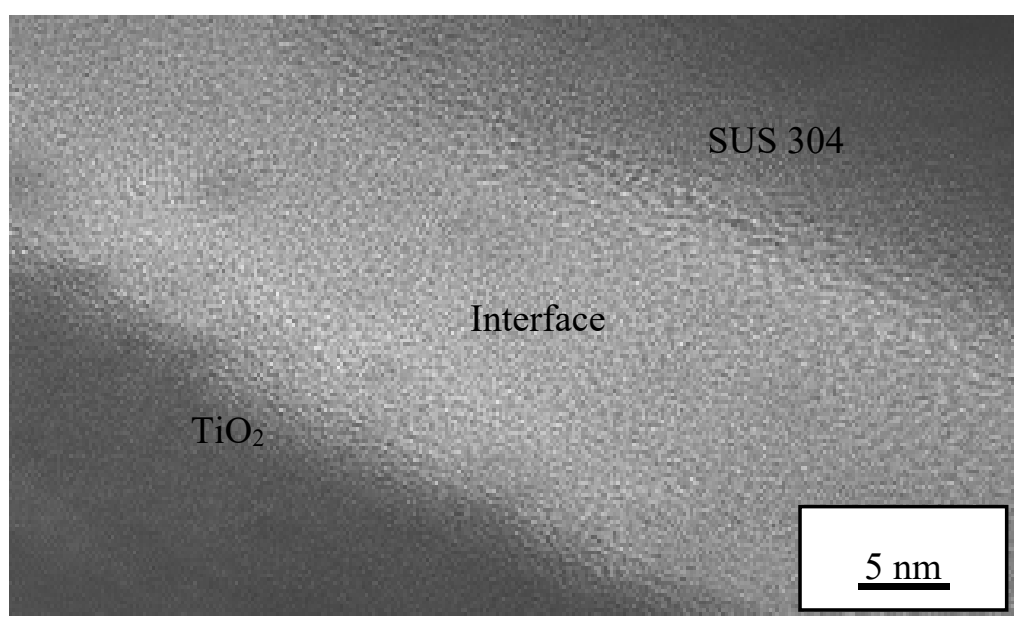

Figure 10. High-magnification images of the $\mathrm{TiO}_{2} / 1000{ }^{\circ} \mathrm{C}$ annealed SUS 304 interface at the bonded region, $\mathrm{B}$.

Further analysis of the EDS (JEOL, Tokyo, Japan) on the rebound region interface layer R showed the elemental composition, as shown in Table 3 and Figure 11. The results showed that the oxide layer that occurs at the interface rebound area, $\mathrm{R}$ of $\mathrm{TiO}_{2}$ particles and $1000{ }^{\circ} \mathrm{C}$ annealed SUS 304 
consist of 96.33 at\% oxygen, 2.35 at $\%$ titanium, 0.95 at \% iron, and 0.38 at $\%$ chromium. In addition, the EDS analysis of the interface layer in the bonded region B reveals the elemental composition, as shown in Table 4 and Figure 12. The results show that the elemental composition was oxygen at 91.88 at $\%$, titanium at 4.22 at $\%$, iron at 2.77 at $\%$, chromium at 0.83 at $\%$, and nitrogen at 0.30 at $\%$. This EDS analysis showed that nitrogen is present in the bonded region $\mathrm{B}$, which is a gas carrier that was used during the cold-spraying process. In addition, at \% of titanium, iron, and chromium in the bonded region $\mathrm{B}$ was also slightly higher than the rebound region $\mathrm{R}$.

Table 3. Chemical composition analysis by EDS for the interface at the rebound region, $\mathrm{R}$ of $\mathrm{TiO}_{2} / 1000{ }^{\circ} \mathrm{C}$ annealed SUS 304.

\begin{tabular}{cc}
\hline Element & Atomic\% \\
\hline $\mathrm{O}$ & 96.33 \\
$\mathrm{Ti}$ & 2.35 \\
$\mathrm{Fe}$ & 0.95 \\
$\mathrm{Cr}$ & 0.38 \\
Total & 100 \\
\hline
\end{tabular}
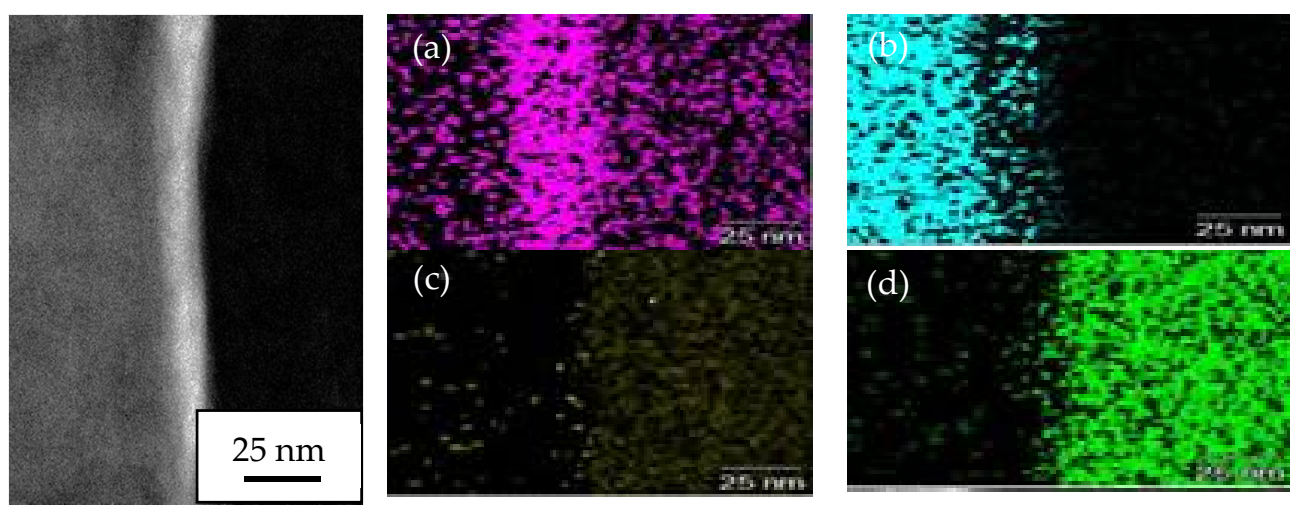

Figure 11. EDX elemental mappings of the $\mathrm{TiO}_{2} / 1000{ }^{\circ} \mathrm{C}$ annealed SUS 304 interface at the rebound region, R: (a) oxygen; (b) titanium; (c) chromium; (d) ferum.

Table 4. Chemical composition analysis by EDS for the interface at the bonded region, $\mathrm{B}$ of $\mathrm{TiO}_{2} / 1000$ ${ }^{\circ} \mathrm{C}$ annealed SUS 304.

\begin{tabular}{cc}
\hline Element & Atomic\% \\
\hline $\mathrm{O}$ & 91.88 \\
$\mathrm{Ti}$ & 4.22 \\
$\mathrm{Fe}$ & 2.77 \\
$\mathrm{Cr}$ & 0.83 \\
$\mathrm{~N}$ & 0.30 \\
Total & 100 \\
\hline
\end{tabular}



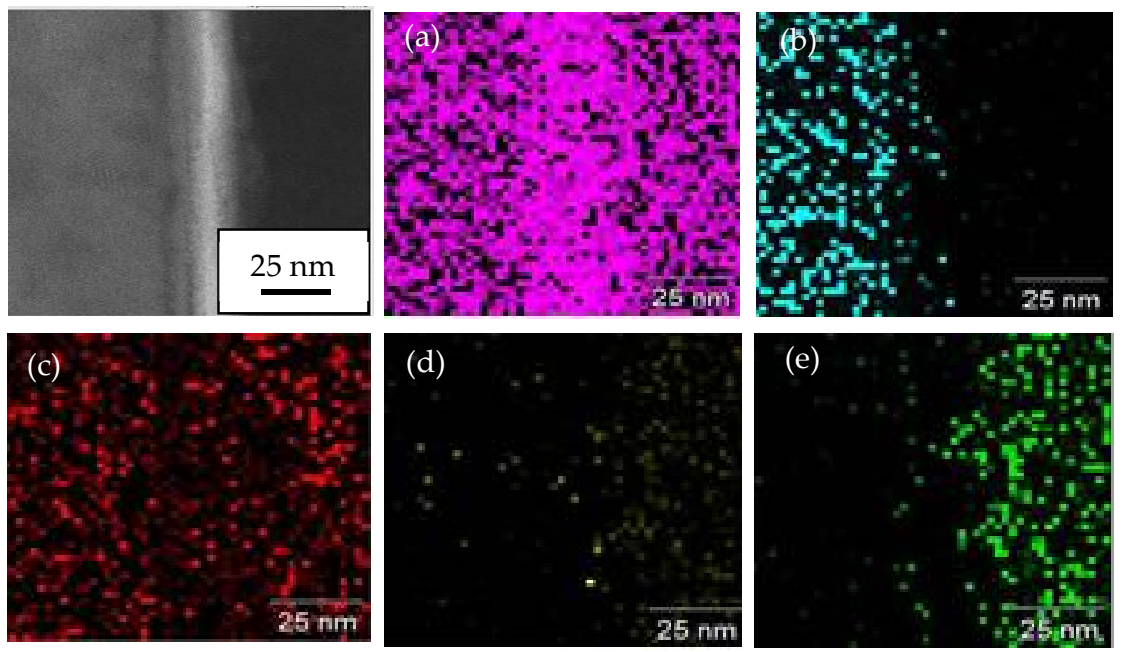

Figure 12. EDX elemental mappings at the $\mathrm{TiO}_{2} / 1000{ }^{\circ} \mathrm{C}$ annealed SUS 304 interface at the bonded region, B: (a) oxygen; (b) titanium; (c) nitrogen; (d) chromium; (e) ferum.

Ko et al. cold-sprayed soft Al particles on the hard, but deformable substrate, Fe. They showed that the atomic intermixing of $\mathrm{Al} / \mathrm{Fe}$ occurring at an amorphous $10 \mathrm{~nm}$ oxide-layer interface could produce a strong adhesive bond between $\mathrm{Al}$ and $\mathrm{Fe}$ due to some of the chemical adhesion forces [2]. They were also cold-sprayed $\mathrm{Cu}$ particles on the AIN substrate and $\mathrm{Al}$ particles on the $\mathrm{ZrO}_{2}$. TEM images show the formation of a $10 \mathrm{~nm}$-thick amorphous layer at the $\mathrm{Cu} / \mathrm{AIN}$ interface and approximately $5 \mathrm{~nm}$ amorphous layer at the $\mathrm{Al} / \mathrm{ZrO}_{2}$ interface. Due to the restructuring of the interfacial layer upon a high-velocity particle impact, the adhesion between the malleable cold-sprayed metals $(\mathrm{Cu}$ and $\mathrm{Al})$ on the brittle ceramic ( $\mathrm{AIN}$ and $\mathrm{ZrO}_{2}$ ) substrate was attributed to the high-velocity collision, instead of mechanical interlocking-resulting in limited amorphization and atomic intermixing. The degree of this type of restructuring depends on particle velocity, hardness, and mechanical deformability that is different between the particle and substrate [22]. Our experiments are consistent with the result (Ko. et al. 2016 [22]) that TEM images showed the formation of an amorphous layer approximately $10-\mathrm{nm}$ from the rebound area of the interface, $\mathrm{R}$ and $15 \mathrm{~nm}$ at the bonded area, B. The EDX results confirm the elemental composition of the amorphous layer consisting of atomic mixing of $\mathrm{Ti} / \mathrm{Fe} / \mathrm{Cr}$. Therefore, atomic intermixing also contributed to the bonding mechanism between the $\mathrm{TiO}_{2} / \mathrm{SUS} 304$ substrate due to some chemical adhesion forces. These findings provide considerable progress related to the bonding mechanism of cold-sprayed $\mathrm{TiO}_{2}$ onto annealed SUS 304 at higher temperatures in terms of explaining the increased adhesion strength of the $\mathrm{TiO}_{2}$ coating as the annealing temperature of the substrate also increased. Substrate deformation and atomic intermixing at the amorphous layer at interface $\mathrm{TiO}_{2} / \mathrm{SUS} 304$ are the two factors involved here.

\section{Conclusions}

This study investigated the correlation between the adhesion strength of cold-sprayed $\mathrm{TiO}_{2}$ on the SUS 304 stainless steel—annealed at temperatures ranging from room temperature to $1000{ }^{\circ} \mathrm{C}$. The results of the study lead to the following conclusions:

- The annealing process plays an important role in the induced ductility of the austenitic stainless steel, SUS 304 especially when annealed at a high temperature such as $1000^{\circ} \mathrm{C}$. This will lead to a decrease in the hardness of the substrate and will make it softer. When the cold-sprayed $\mathrm{TiO}_{2}$ particle is impacted with a high velocity on the annealed $1000^{\circ} \mathrm{C}$ SUS 304 surface, the plastic deformation of the substrate occurs and provides a large continuous contact zone between the particles and the substrate, resulting in bonding. Therefore, the adhesion strength of the $\mathrm{TiO}_{2}$ coating is high on the annealed $1000{ }^{\circ} \mathrm{C}$ SUS 304 substrate. 
- The oxide layer of austenitic stainless steel, SUS 304 grows thicker as the annealed temperature of the substrate increases. The TEM/EDX result shows that the existence of the remaining interface of the amorphous layer is approximately $10 \mathrm{~nm}$ for the rebound region, $R$ and $15 \mathrm{~nm}$ for the bonded region, B between the $\mathrm{TiO}_{2}$ particles and $1000{ }^{\circ} \mathrm{C}$ annealed SUS 304. Due to the restructuring of the interfacial layer upon a high-velocity particle impact, the adhesion between the brittle $\mathrm{TiO}_{2}$ particle and the stainless steel SUS 304 metal was attributed to a high-velocity collision and resulted in limited amorphization and atomic intermixing. Atomic intermixing of $\mathrm{Ti} / \mathrm{Fe} / \mathrm{Cr}$ at the interface may produce a strong adhesive bond between them due to chemical adhesion forces.

Author Contributions: Conceptualization and methodology, N.I.O., S.S., and M.K.; formal analysis, investigation, data curation, and writing - original draft preparation, N.I.O.; writing-review and editing, M.Y.; supervision, T.Y. and M.F.; funding acquisition, M.Y. All authors have read and agreed to the published version of the manuscript.

Funding: This research is supported by JSPS KAKENHI, grant number JP17K06857 and was partially carried out at the Cooperative Research Facility Center at Toyohashi University of Technology.

Acknowledgments: We also acknowledge the Interface and Surface Fabrication lab, Majlis Amanah Rakyat, and the Technical University of Malacca for Noor Irinah's PhD scholarship.

Conflicts of Interest: The authors declare no conflict of interest.

\section{References}

1. Champagne, V.K. The Cold Spray Materials Deposition Process Fundamentals and Applications, 1st ed.; Victor, K.C., Ed.; Woodhead Publishing Limited: Cambridge, UK, 2007; Introduction; pp. 1-2.

2. Ko, K.; Choi, J.; Lee, H. Intermixing and interfacial morphology of cold-sprayed Al coatings on steel. Mater. Lett. 2014, 136, 45-47. [CrossRef]

3. Xie, Y.; Planche, M.-P.; Raoelison, R.; Liao, H.; Suo, X.; Hervé, P. Effect of Substrate preheating on adhesive strength of SS 316L cold spray coatings. J. Therm. Spray Technol. 2015, 25, 123-130. [CrossRef]

4. Yamada, M.; Isago, H.; Nakano, H.; Fukumoto, M. Cold spraying of $\mathrm{TiO}_{2}$ photocatalyst coating with nitrogen process gas. J. Therm. Spray Technol. 2010, 19, 1218-1223. [CrossRef]

5. Winnicki, M.; Baszczuk, A.; Jasiorski, M.; Borak, B.; Małachowska, A. Preliminary studies of $\mathrm{TiO}_{2}$ nanopowder deposition onto metallic substrate by low pressure cold spraying. Surf. Coatings Technol. 2019, 371, $194-202$. [CrossRef]

6. Winnicki, M.; Jasiorski, M.; Baszczuk, A.; Borak, B. Preliminary studies of TiO2 coatings by deposition onto ABS polymer substrates by low pressure cold spraying. In Proceedings of the Les Rencontres Internationales sur la Projection Thermique-RIPT 9, Jülich, Germany, 11-13 December 2019.

7. Hajipour, H.; Abdollah-Zadeh, A.; Assadi, H.; Taheri-Nassaj, E.; Jahed, H. Effect of feedstock powder morphology on cold-sprayed titanium dioxide coatings. J. Therm. Spray Technol. 2018, 27, 1542-1550. [CrossRef]

8. Schmidt, K.; Buhl, S.; Davoudi, N.; Godard, C.; Merz, R.; Raid, I.; Kerscher, E.; Kopnarski, M.; Renno, C.M.; Ripperger, S.; et al. Ti surface modification by cold spraying with $\mathrm{TiO}_{2}$ mircoparticles. Surf. Coat. Technol. 2017, 309, 749-758. [CrossRef]

9. Kliemann, J.-O.; Gutzmann, H.; Gärtner, F.; Hübner, H.; Borchers, C.; Klassen, T. Formation of cold-sprayed ceramic titanium dioxide layers on metal surfaces. J. Therm. Spray Technol. 2010, 20, 292-298. [CrossRef]

10. Gutzmann, H.; Freese, S.; Gartner, F.; Klassen, T. Cold gas spraying of ceramics using the example of titanium dioxide. In Proceedings of the nternational Thermal Spray Conference, ITSC, Hamburg, Germany, 27-29 September 2011; pp. 391-396.

11. Gardon, M.; Fernández-Rodíguez, C.; Garzón Sousa, D.; Doña-RodRíguez, J.M.; Dosta, S.; Cano, I.G.; Guilemany, J.M. Photocatalytic activity of nanostructured anatase coatings obtained by cold gas spray. J. Therm. Spray Technol. 2014, 23, 1135-1140. [CrossRef]

12. Salim, N.T.; Yamada, M.; Nakano, H.; Shima, K.; Isago, H.; Fukumoto, M. The effect of post-treatments on the powder morphology of titanium dioxide $\left(\mathrm{TiO}_{2}\right)$ powders synthesized for cold spray. Surf. Coatings Technol. 2011, 206, 366-371. [CrossRef]

13. Clayton, C.R. Materials science and engineering: An introduction. Mater. Sci. Eng. 1987, 94, $266-267$. [CrossRef] 
14. Trompetter, B.; Hyland, M.; McGrouther, D.; Munroe, P.; Markwitz, A. Effect of substrate hardness on splat morphology in high-velocity thermal spray coatings. J. Therm. Spray Technol. 2006, 15, 663-669. [CrossRef]

15. Yin, S.; Wang, X.; Suo, X.; Liao, H.; Guo, Z.; Li, W.; Coddet, C. Deposition behavior of thermally softened copper particles in cold spraying. Acta Mater. 2013, 61, 5105-5118. [CrossRef]

16. Assadi, H.; Gärtner, F.; Stoltenhoff, T.; Kreye, H. Bonding mechanism in cold gas spraying. Acta Mater. 2003, 51, 4379-4394. [CrossRef]

17. Grujicic, M.; Zhao, C.I.; De Rosset, W.S.; Helfritch, D. Adabatic shear instability based mechanism for particle/substrate bonding in the cold-gas dynamic-spray process. Mater. Des. 2004, 25, 681-688. [CrossRef]

18. Bae, G.; Xiong, Y.; Kumar, S.; Kang, K.; Lee, C. General aspects of interface bonding in kinetic sprayed coatings. Acta Mater. 2008, 56, 4858-4868. [CrossRef]

19. Yin, S.; Wang, X.-F.; Li, W.Y.; Jie, H.-E. Effect of substrate hardness on the deformation behavior of subsequently incident particles in cold spraying. Appl. Surf. Sci. 2011, 257, 7560-7565. [CrossRef]

20. Kim, K.; Li, W.; Guo, X. Detection of oxygen at the interface and its effect on strain, stress, and temperature at the interface between cold sprayed aluminum and steel substrate. Appl. Surf. Sci. 2015, 357, 1720-1726. [CrossRef]

21. Kim, K.; Kuroda, S. Amorphous oxide film formed by dynamic oxidation during kinetic spraying of titanium at high temperature and its role in subsequent coating formation. Scr. Mater. 2010, 63, 215-218. [CrossRef]

22. Ko, K.; Choi, J.; Lee, H. The interfacial restructuring to amorphous: A new adhesion mechanism of cold-sprayed coatings. Mater. Lett. 2016, 175, 13-15. [CrossRef]

Publisher's Note: MDPI stays neutral with regard to jurisdictional claims in published maps and institutional affiliations.

(C) 2020 by the authors. Licensee MDPI, Basel, Switzerland. This article is an open access article distributed under the terms and conditions of the Creative Commons Attribution (CC BY) license (http://creativecommons.org/licenses/by/4.0/). 